\title{
Психофизиология
}

Данилова Н.Н

\section{Частотная специфичность осцилляторов гамма ритма}

Работа выполнена при поддержке РФФИ (грант № 01-06-80202)

B статье анализируются исследования гамма-ритма, послужившие основанием для появления и широкого распространения конщепции связывания различных нейронных сетей в единую систему через механизм синхронизации гамма-ритма. Автор предлагает собственное исследование синхронизации активности у узкополосных гамма осиилляторов, остро настроенных на определенную частоту в условиях, которые стимулируют усиление гамма-ритма. Была применена новая технология, позволившая получить более точные данные о мозговой локализации диполей гамма-ритма за счет их проекиии на томографические срезы индивидуального мозга.

Ключевые слова: гамма ритм, синхронизация, гамма осиилляторы, коммуникативная функиия гамма-ритма, вставочные нейронов

Гамма ритм - высокочастотная активность мозга, регистрируемая у человека в составе ЭЭГ, все больше и больше привлекает внимание исследователей. Повышенный интерес к гамма ритму обусловлен тем, что различные виды когнитивных процессов сопровождаются усилением активности в частотном диапазоне гамма ритма, который простирается от 30 до 200 Гц, а по некоторым данным и до 600 Гц [31].

Отмечена связь гамма ритма с восприятием и опознанием стимула, возникновением иллюзий, формированием гештальта $[1,4$, $13,35,38]$. Усиление гамма ритма наблюдали не только при работе с сенсорной, но и семантической информацией $[25,30]$.

Гамма ритм связан с выполнением двигательных реакций. Вспышки гамма ритма появляются в моторной и премоторной коре, дополнительном моторном поле и в париетальной коре человека до 
начала движения, продолжаются во время его исполнения и дополнительно появляются на прекращение движения. Высказана гипотеза о том, что гамма-ритм имеет отношение и к торможению двигательной реакции на нецелевой стимул [27, 29, 32].

В опытах с периодами задержки, в течение которых требуется удерживать информацию о ранее предъявляемом целевом стимуле для последующего его опознания, показана связь гамма-ритма с процессами сохранения информации в рабочей памяти. В работе [39] представлены убедительные доказательства связи активности гаммаритма с эффективностью сохранения информации в памяти. На всем протяжении периода задержки при сохранении информации о зрительном стимуле исследователи наблюдали устойчивое увеличение мощности гамма осцилляций (24-60 Гц) в зрительной коре и бета осцилляций (15-20 Гц) во фронтальной. С удлинением периода задержки осцилляции ослабевали, что совпадало с параллельным ухудшением результатов опознания целевого стимула.

Включенность гамма ритма в самые различные сенсорные, когнитивные и исполнительные процессы, наличие его не только в мозге человека, но и у животных, включая беспозвоночных, позволило Е. Басару рассматривать гамма ритм в качестве функциональных строительных блоков, используемых в интегративной деятельности мозга и психических функциях $[8,9]$.

Важным этапом на пути изучения причастности гамма-ритма к процессам обработки информации явилось открытие фазовой синхронизации гамма осцилляций в полосе 35-85 Гц, возникающей между удаленными участками зрительной коры кошки [12]. Позже этот факт был подтвержден существованием межколонковой синхронизации спайковой активности нейронов зрительной коры кошки на частоте гамма осцилляций, возникающей при восприятии зрительных стимулов (Gray et al., 1989). Нейроны пространственно удаленные, но обладающие одинаковыми детекторными свойствами, селективно настроенные реагировать на перемещение полоски в определенном направлении и с определенной скоростью, в ответ на эту стимуляцию синхронно и без фазовой задержки разряжались пачками ПД, повторяющимися с частотой 40-Гц гамма-ритма.

Эта и последующие работы послужили основанием для появления и широкого распространения концепции связывания (binding) различных нейронных сетей в единую систему через механизм синхронизации гамма-ритма. Первоначально речь шла о 
том, что когерентные гамма осцилляции отражают механизм зрительной коры, обеспечивающий интеграцию различных черт объекта для воссоздания его образа, формирование гештальта $[14,23]$. Позже синхронизация осцилляторной активности удаленных локусов мозга на частоте гамма-ритма стала рассматривается как более универсальный и основной механизм коммуникации между нейронными сетями, который обеспечивает самые разные виды взаимодействия между сенсорными, исполнительными и когнитивными процессами, включая память [8].

Следует отметить, что во многих работах заключение о синхронизации гамма осцилляций как основном механизме связывания делалось на основе измерения амплитуды или мощности гамма-ритма, без измерения фазовых отношений между гамма осцилляциями. Однако ошибочно относить изменение мощности к синхронизации, так как мощность и фаза - два независимых измерения осцилляторной активности. Синхронизация имеет дело с фазовыми отношениями и ничего общего с мощностью. Фазовая синхронизация гамма осцилляций может возникать и без какого либо увеличения их мощности. Синхронизацию нейронных разрядов в зрительной коре кошки наблюдали без изменения в частоте их разрядов [17, 19].

Связывание должно быть быстрым процессом и естественно ожидать, что оно использует активность высокочастотных нейронных сетей. Отличительной чертой гамма осцилляций, которая позволяет его рассматривать как основу для связывания, является не возникновение или усиление гамма осцилляций, а скорее тот факт, что осцилляции в различных нейронных популяциях частотно синхронизированы или связаны по фазе [10, 33, 41].

Оценка фазовых отношений гамма осцилляций между различными отведениями путем вычисления когерентности по многоканальной ЭЭГ или МЭГ является одним из успешно развиваемых методов изучения причастности гамма осцилляций к связыванию и управлению взаимодействием процессов в мозге. Другой путь- использование вычисления УВП с последующей частотной фильтрацией в полосе гамма-ритма $[20,44]$. Каждый из упомянутых методов вычисляет разные типы синхронизации гамма активности.

Метод вычисления когерентности измеряет фазовую синхронизацию, возникающую между различными отведениями 
электрической активности мозга, а именно пространственную синхронизацию. Однако он игнорирует фазовые отношения гамма осцилляций со стимулом.

С помощью УВП исследуется вызванный гамма-ритм, характеризующийся фазовый привязкой к стимулу. Согласно классификации Галамбоса его следует отличать от индуцированного гамма-ритма. Последний по фазе не синхронизирован со стимулом, так как инициируются другими, внутренними факторами, которые по времени не совпадают с предъявлением внешних стимулов [18]. Метод УВП, оценивая фазовую синхронизацию гамма осцилляций со стимулом, не измеряет синхронизацию гамма-ритма по пространству.

Эти недостатки методов могут быть устранены при изучении вызванного гамма-ритма методом дипольного анализа. Дипольный анализ учитывает факт пространственной синхронизации гамма осцилляций, так как при нахождении эквивалентного диполя для осцилляций учитывается информация от множества электродов. Решение о наличии дипольного источника принимается на основе синхронного появления гамма-осцилляций под многими электродами. Соединение дипольного анализа с методом УВП позволяет одновременно учитывать как пространственную синхронизацию гамма осцилляций, так и их фазовую привязку к стимулу.

Кроме того дипольный анализ позволяет для любой формы мозговой активности, включая гамма осцилляции, определять локализацию их точечных источников в трехмерном объеме мозга. Алгоритм локализации основан на гипотезе о том, что в мозге существуют точечные источники электрической активности, локально распределенные по его структурам. Электрическая активность, в каждый момент времени регистрируемая многими электродами от скальпа, рассматривается как результат пространственной суммации электрических полей этих источников, пассивно распространяющихся по мозгу, как объемному проводнику. Решение обратной задачи и позволяет находить с некоторой степенью достоверности пространственное положение эквивалентных дипольных источников для выбранной формы электрической активности мозга.

При высокой частоте оцифровки ЭЭГ дипольный анализ выявляет временную динамику гамма осцилляций в составе УВП с высоким временным разрешением. Все сказанное позволяет рассматривать соединение методов УВП и дипольного анализа как одно из перспективных направлений изучения функций гамма осцилляций в интегративной деятельности мозга [1-4]. 
При большом интересе исследователей к гамма-ритму, что отражается в ежегодном увеличении числа публикаций, посвященных его изучению, многие вопросы продолжают оставаться без ответа. Не ясен, ни сам механизм генерации гамма осцилляций, ни способы, которыми синхронизированный гамма-ритм включается в самые разнообразные мозговые операции. Требует объяснения и факт появления гамма осцилляций в различных частотных диапазонах. Имеется совсем мало работ, фиксирующих внимание на связи частоты осцилляций со структурами и функциями мозга.

Только в ряде работ отмечена привязка отдельных структур мозга к определенным частотным диапазонам гамма-ритма. В ольфакторной системе саранчи осцилляции, чувствительные к запаху, возникают в пределах полосы 20-34 Гц [25, 37, 42]. У человека сходная частотная избирательность к запаху обнаружена в полосе частот 33-44 Гц, регистрируемых от ольфакторной луковицы, усиление которых отчетливо коррелирует с субъективным восприятием запаха [21].

В зрительной системе позвоночных осцилляторные ответы возникают последовательно в ретине, ЛКТ и зрительной коре. Их сравнение показывает, что для их генерации в каждой структуре используются разные частотные диапазоны. У простых и сложных нейронов-детекторов 17 и 18 полей кошки и обезьяны в ответ на предъявление оптимально ориентированной световой полоски возникают осцилляции на частоте 20-80 Гц с пиком на 40 Гц. Более высокие частоты 50-100 Гц записаны у тех же животных от первичной зрительной коры в ответ на более сложные стимулы: движущиеся полоски и решетки $[11,14,16]$. У обезьяны эти осцилляции обнаружены в мультиклеточных спайках и в фокальных потенциалах стриарной (V1) и экстрастриарной (V2) коры с фазовым различием близким к нулю [16]. Ганглиозные клетки сетчатки и нейронов ЛКТ реагируют на вспыхивающие или движущиеся полоски, а также решетки появлением осцилляций на частоте 60-120 Гц, значительно более высокой, чем в коре [28].

Частотная селективность гамма ритма, привязка его различных частотных диапазонов к этапам формирования двигательного навыка продемонстрирована в работах В.Н. Думенко с сотрудниками $[5,6]$. На основе исследования высокочастотных составляющих электрокортикограммы $(30-200 \quad$ Гц $)$ в процессе выработки инструментального двигательного навыка у собак, они пришли к выводу о негомогенности гамма ритма. Разделяя частотные диапазоны 
на полосы шириной в 15 Гц, авторы показали, что энергия отдельных полос меняется независимо. У собак, успешно вырабатывающих навык, в ответ на условный сигнал увеличивалась мощность гамма ритма в полосе частот 80-200 Гц при параллельном снижении активности на частотах 30-80 Гц. Эта связь частоты гамма ритма с функцией отсутствовала у животных с плохо выработанным навыком.

Рассмотренные выше публикации не дают ответа на вопрос как далеко идет частотная независимость гамма осцилляторов. Чтобы пролить свет на эту проблему, мы исследовали синхронизацию активности у узкополосных гамма осцилляторов, остро настроенных на определенную частоту, в условиях, которые стимулируют усиление гамма-ритма. Была применена новая технология изучения вызванного гамма-ритм - метод УВП соединен с дипольным анализом и анатомической магнитно-резонансной томографией мозга. Последняя позволяла получать более точные данные о мозговой локализации диполей гамма-ритма за счет их проекции на томографические срезы индивидуального мозга.

Гамма-ритм был исследован в трех экспериментальных ситуациях. В одной - человек пассивно воспринимал звуковые щелчки (индифферентная серия) и выполнял сенсомоторную реакцию на выключение звука (моторная серия). В другом типе эксперимента человек должен был перемножать в уме в быстром темпе пары чисел, которые ему предъявлялись через наушники, произносимые женским голосом. В третьей экспериментальной ситуации на экран монитора предъявлялись зрительные стимулы, среди которых нужно было опознавать зрительные целевые стимулы (появление яркого светового квадрата) и отвечать на них двигательной реакцией.

В сериях с пассивным прослушиванием звуковых щелчков и выполнением моторной реакции на выключение звука предъявлялось 120 стимулов длительностью в 130 мс, следующих с постоянным межстимульным интервалом в 1,5 с. В опытах приняли участие 5 человек (3 женщин и 2 мужчин) в возрасте 18 -24 лет. Эксперименты с перемножением чисел выполнены на 12 испытуемых (женщинах в возрасте 24-27 лет). 100 пар двухзначных чисел предъявлялось через наушники женским голосом, средняя продолжительность звукового стимула - 2,3 с. Межстимульный интервал 8 секунд. В серии со зрительными стимулами испытуемый должен был нажимать на клавишу после целевого стимула - белого квадрата, возникающегося в правом или в левом поле зрения. Дифференцировочным стимулом 
был серый квадрат появляющийся одновременно справо и слева. Длительность стимулов - 1 с. Эксперимент проведен на 10 испытуемых в возрасте 18-23 лет.

Во всех трех экспериментах исследовался гамма-ритм в составе усредненных звуковых и световых УВП, то есть вызванный гамма ритм, который синхронизирован по фазе со стимулом. Для извлечения гамма-ритма из УВП применяли метод частотной фильтрации.

Регистрация ЭЭГ производилась с помощью компьютерной системы "Brainsys" фирмы НМФ "Статокин" (Россия). 15-канальная запись ЭЭГ осуществлялась по международной системе $10-20 \%$ с отведениями в $\mathrm{O} 2, \mathrm{O} 1, \mathrm{P} 4, \mathrm{P} 3, \mathrm{C} 4, \mathrm{C} 3, \mathrm{CZ}, \mathrm{T} 6, \mathrm{~T} 5, \mathrm{~T} 4, \mathrm{~T} 3, \mathrm{~F} 4, \mathrm{~F} 3, \mathrm{~F} 8$, F7. В качестве референтного использовался объединенный ушной электрод. Частота оцифровки ЭЭГ 400 Гц. Полоса пропускания 0,3-80 Гц сигнала. Применялся запирающий фильтр, вырезающий 50-Гц колебания, связанные с сетевой наводкой.

Исследовалось поведение узкополосных гамма осцилляторов при ширине частотной настройки в 1 Гц. Для этого УВП, полученные для каждой серии, подвергались узкополосной фильтрации шириной в 1 Гц в двух частотных полосах: 30-45 и 55-75 Гц.

Для определения трехмерной локализации в мозге гамма осцилляторов метод дипольного анализа соединялся с анатомической магнитно-резонансной томографией. Расчет координат эквивалентного диполя тока для гамма осциллятора производился по программе Brainloc (модель одного подвижного диполя). При частоте оцифровки ЭЭГ в 400 Гц, вычисление наличия дипольного источника производилось каждые 2,5 мс. Рассчитанные по 15-канальной ЭЭГ координаты источников гамма осцилляций проецировались на изображения аксиальных томографических срезов мозга конкретных испытуемых, полученных на магнитно-резонансной томографе TOMIKON S50 (BRUKER) в ЦМТС МГУ.

Для получения структурных магнитно-резонансных срезов мозга испытуемых использовалась методика 3D-градиентного эха, которая позволила обеспечить высокое пространственное разрешение не хуже 1 мм по всему объему головного мозга испытуемых. Применение градиентного эха является альтернативой послойному сканированию объекта при МРТ исследованиях. Благодаря 3D- методике удается построить 
неискаженные по контрасту изображения для тонких слоев порядка 1 мм, что не удается пока реализовать при послойном сканировании из-за артефактов, обусловленных наложением сигналов от соседних слоев. В результате за короткое время ( 30 мин.) получается полное 3-мерное изображение головного мозга.

Уровень суммарной активности гамма осциллятора, настроенного на определенную частоту, оценивался числом его дипольных источников, выявленных на определенном интервале времени при коэффициенте дипольности (КД) равном 0,95. Подсчет числа диполей производилась в объеме целого мозга, независимо от того в каких структурах мозга они были обнаружены.

В более ранних наших работах вызванный гамма-ритм исследовался методом широкополосной частотной фильтрации шириной в 15 Гц в частном диапазоне от 30 до 45 Гц,. В сериях с восприятием звуковых щелчков широкополосная фильтрация звукового УВП, полученного для 120 звуковых стимулов, у всех испытуемых выявляет наличие так называемого сенсорного ответа - вспышки гамма осцилляций на интервале 0-100 мс после стимула, которая практически возникает во всех отведениях ЭЭГ. Сенсорный ответ гамма-ритма можно было наблюдать как в индифферентной, так и в моторной серии $[1,2,4]$. На рис.1 представлен сенсорный ответ гамма-ритма, полученный в результате широкополосной частотной фильтрации звукового УВП у одного из испытуемых.

При использовании фильтрации УВП в узкой полосе частот резко увеличилось число выявляемых дипольных источников гамма осцилляторов с острой настройкой в сравнении с результатами, полученными при широкополосной фильтрации. При сужении полосы фильтрации с 15 Гц до 1 Гц (на шкале частот 30-45 Гц) у всех испытуемых число активно работающих гамма осцилляторов увеличивалось как в индифферентной, так и моторной сериях. 


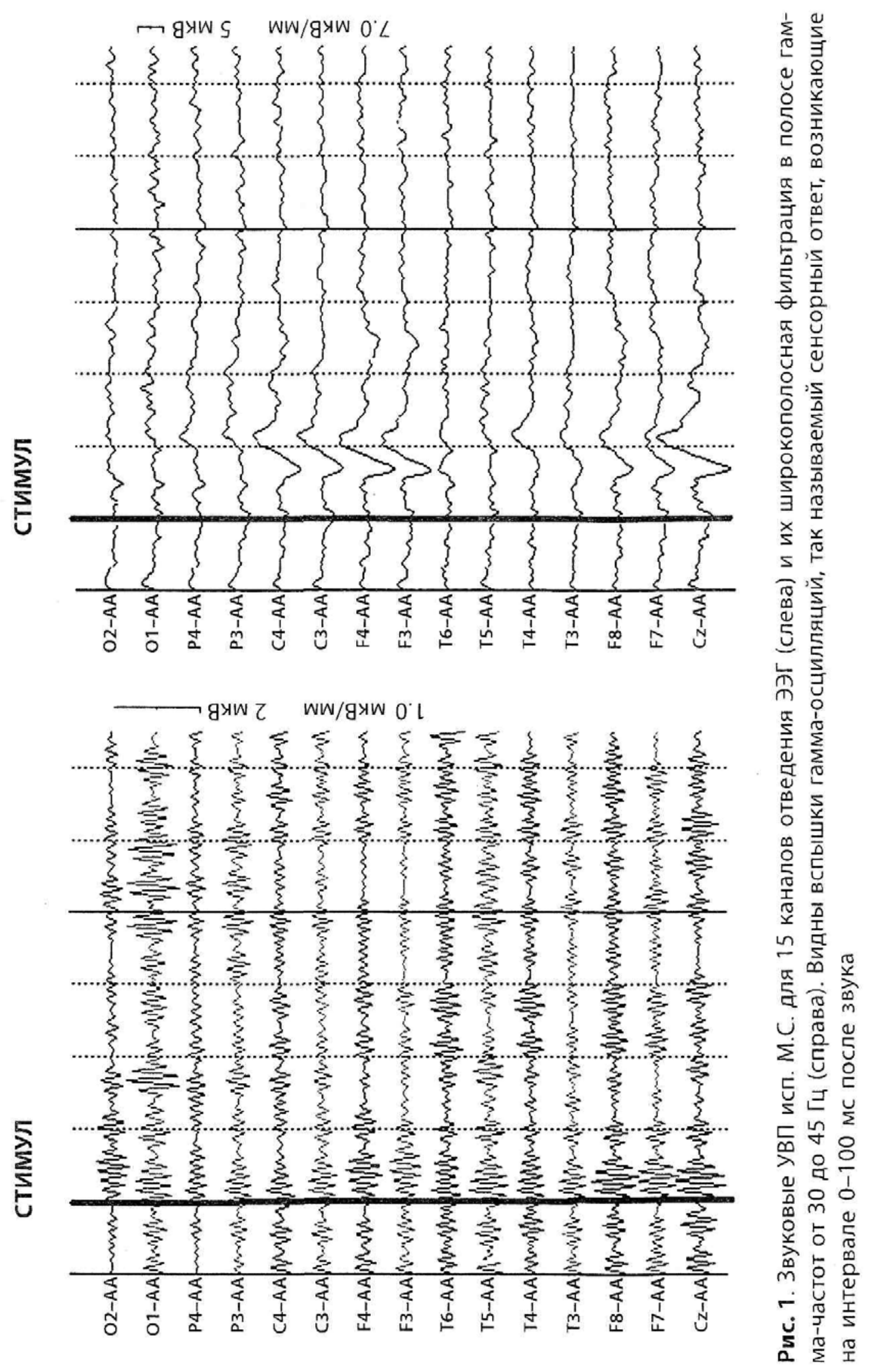




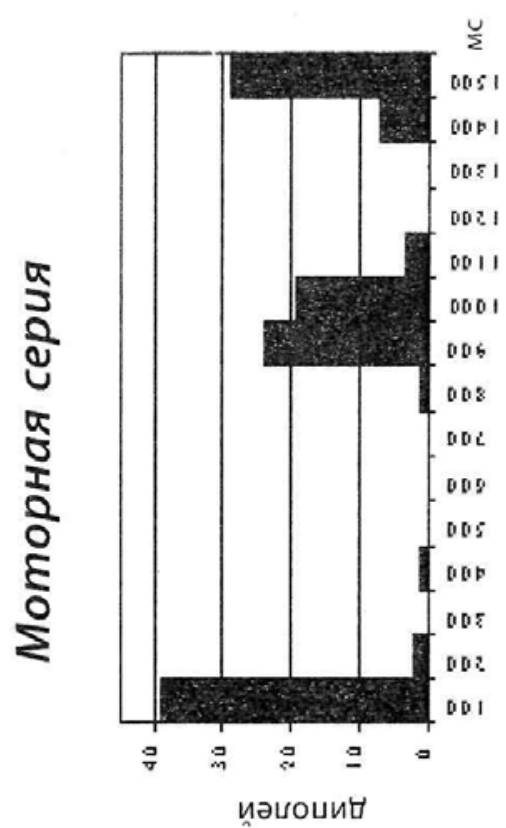

ХІवнцнәчеяияче

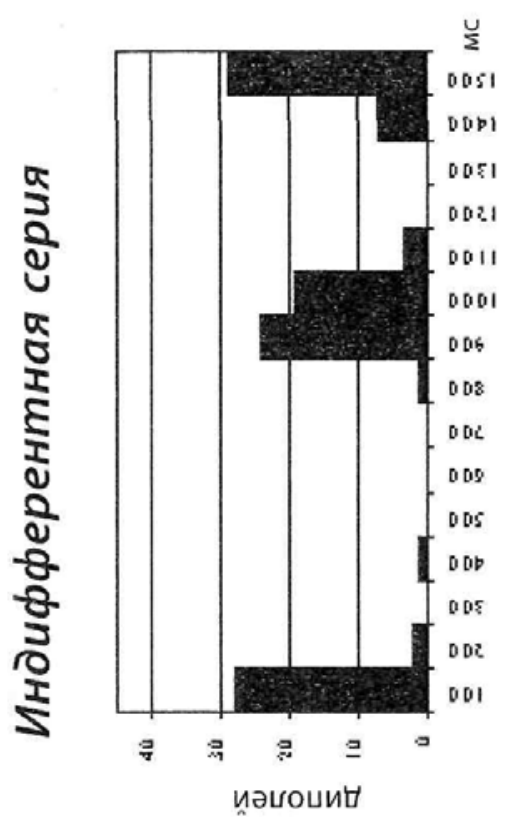

ХІवнцнวчеяияче

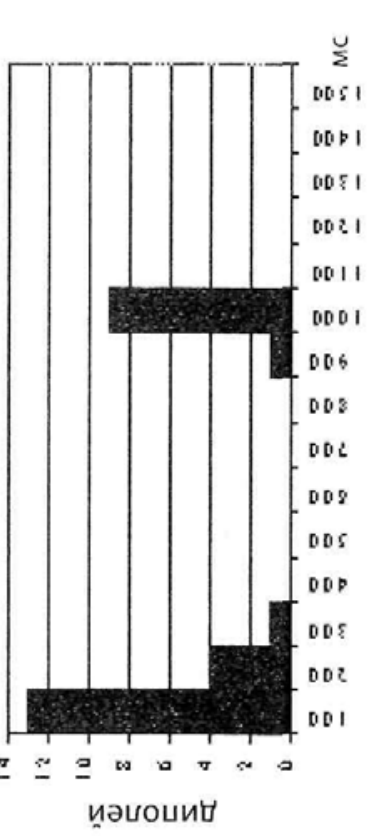

ХІवнАнәчеgияче

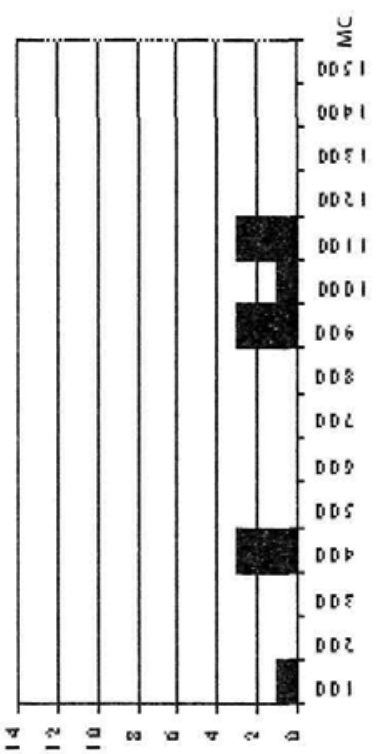

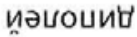

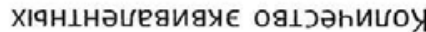

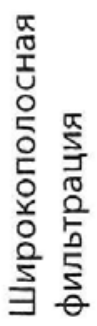

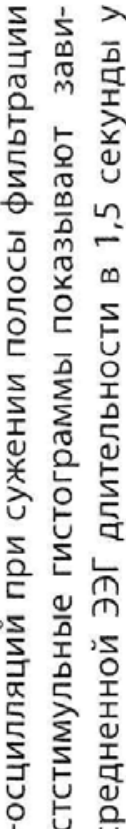

1은 는

$\sum_{1} 48$

튼

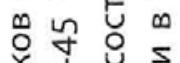

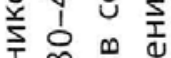

宁

论

$\times$ 当道

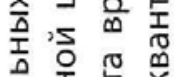

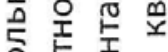

은 은

可皆

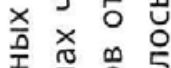

I

空

을 夌

당

我尖

先。

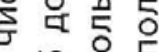

는 든

兵证

売

(4) 元

$\infty$ 인

ن

ن 
На рис.2 представлены постстимульные гистограммы (ПСГ) для усредненных ЭЭГ длительностью в 1,5 с, характеризующие временное распределение числа локализованных в мозге узкополосных и широкополосных гамма осцилляторов в двух сериях у одного из испытуемых. Видно, что число осцилляторов с острой настройкой в десятки раз превосходит количество диполей, получаемых при широкополосной фильтрации усредненной ЭЭГ. При этом ПСГ, полученные двумя методами обнаруживают значительное сходство: фазы активации и инактивации возникают на одних и тех же временных участках. В тоже время у осцилляторов с острой настройкой заметнее выражена фаза активности, предшествующая моменту предъявления стимула или реакция антиципации.

Исследование поведения 15 узкополосных гамма осцилляторов как в составе сенсорного ответа, так и на протяжении всего УВП и даже более длительного участка усредненной ЭЭГ в 1,5 секунды выявило частотно избирательный характер активности гамма осцилляторов с острой настройкой.

На рис. 3 представлены УВП и результаты его широкополосной (в полосе частот 30-45 Гц) и узкополосной частотной фильтрации шириной в 1 Гц в пределах того же частотного диапазоне. Видно, что вспышки узкополосного гамма-ритма разных частот имеют не одинаковую амплитуду.

Основной вклад в состав сенсорного ответа гамма-ритма вносят частоты 37, 38, 39 и 40 Гц. При этом осцилляции на этих частотах появляются еще до стимула, отражая формирование реакции антиципации, что достаточно часто возникает в условиях многократного повторения звука с фиксированным межстимульным интервалом.

Частотно-избирательный характер активности гамма осцилляторов выявлен не только на начальном участке УВП (0-100 мc). Он присутствует и на протяжении всей усредненной ЭЭГ длительностью в 1,5 секунды. На рис. 4 представлена типичная гистограмма частотно-временного распределения активности узкополосных гамма осцилляторов в составе такой усредненной ЭЭГ, полученной для серии с индифферентными звуковыми щелчками.

Уровень активности каждого узкополосного гамма осциллятора измерялся суммарным числом его дипольных источников, подсчитанным для каждого временного окна УВП величиной в 100 мс при коэффициенте дипольности в 0,95. Подсчет диполей велся в объеме целого мозга независимо от того, в каких структурах мозга они были локализованы. 


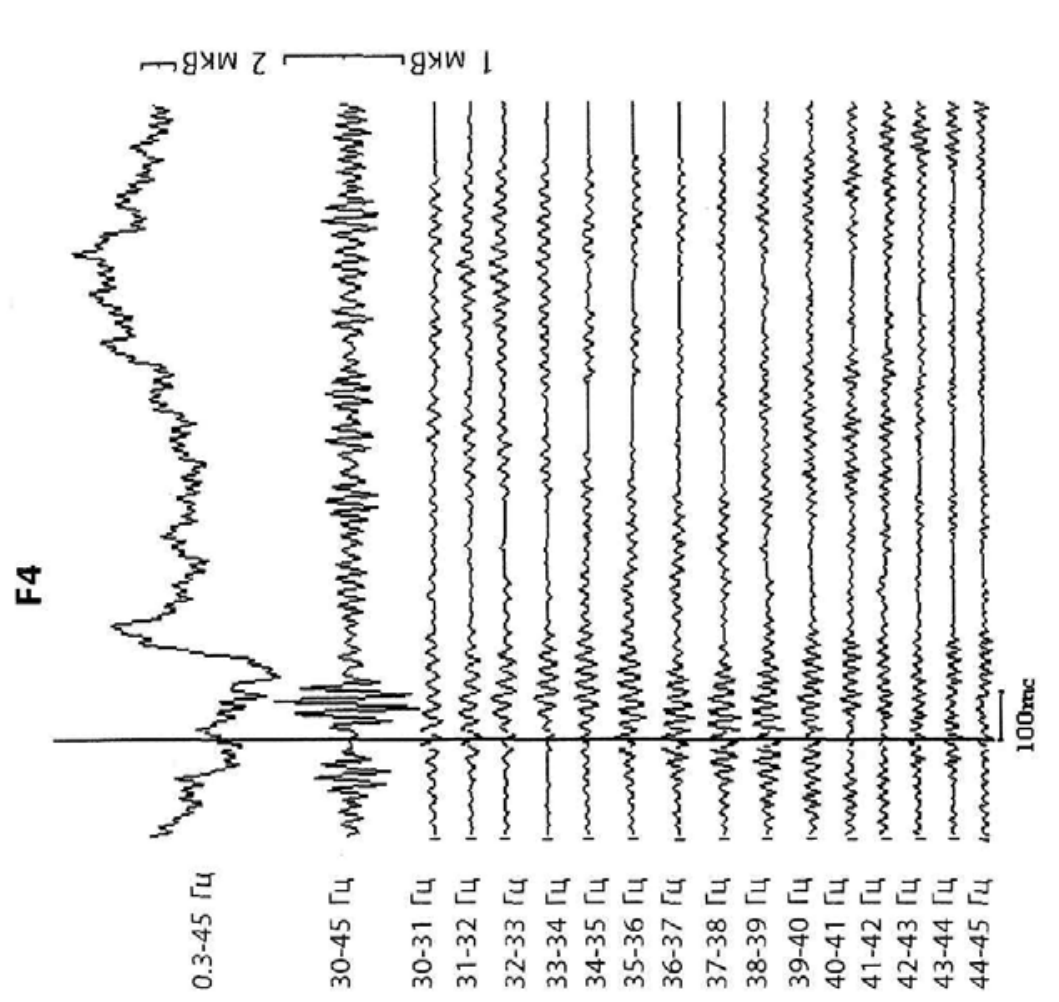

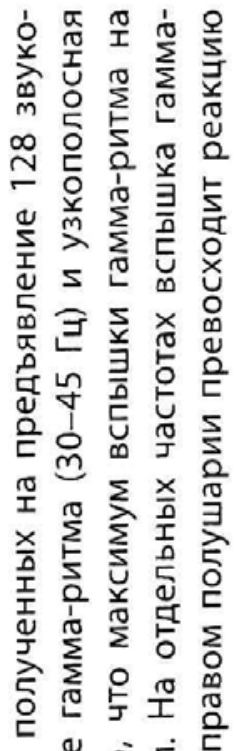

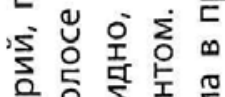

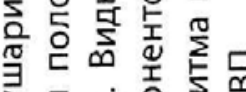

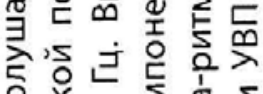

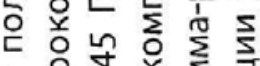

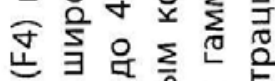
잉

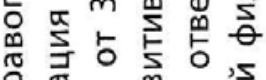

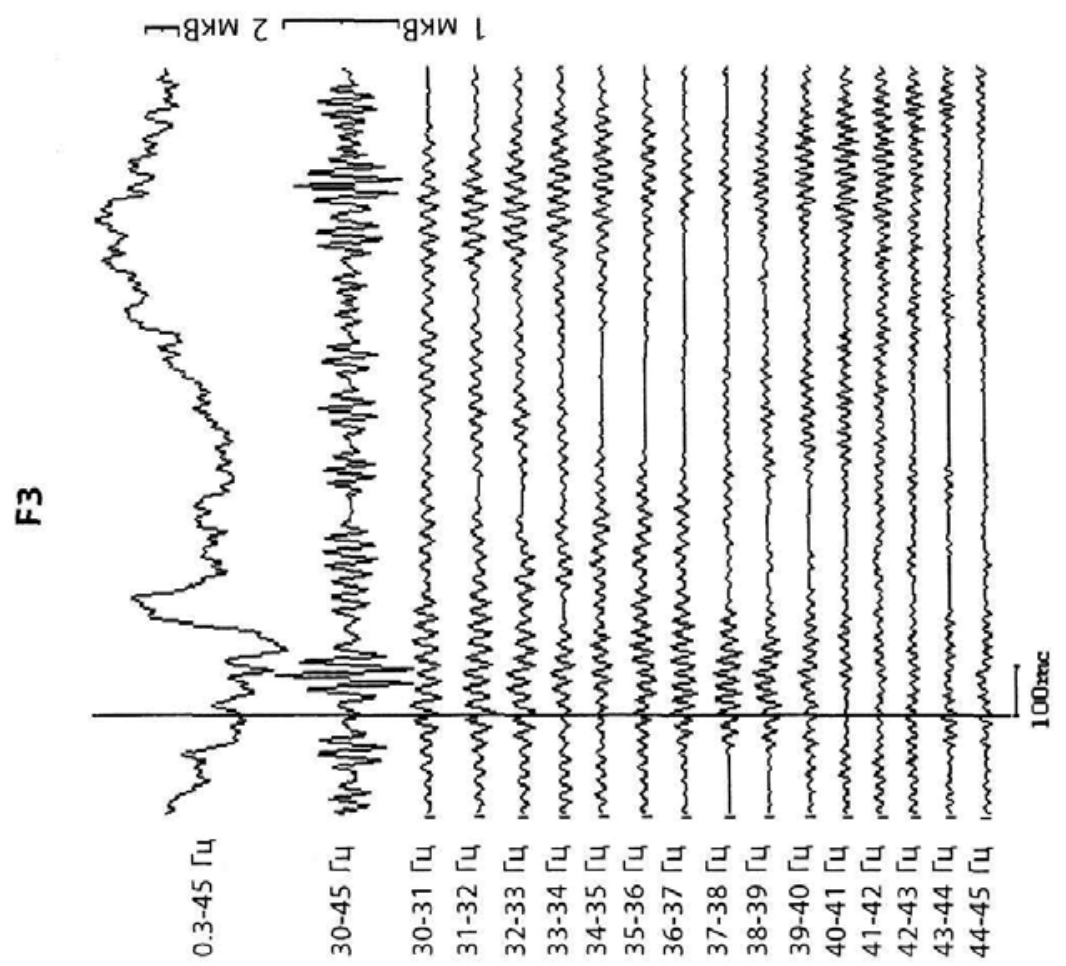

읃 증 잉응 웅 s

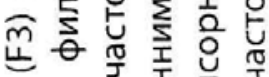
은 留

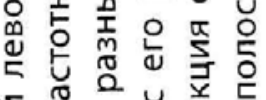

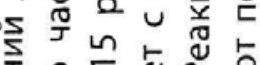

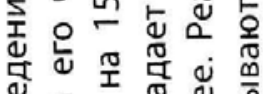

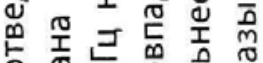
梁-

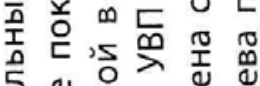

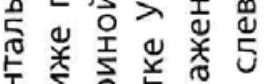

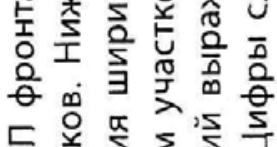
采率咢

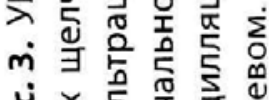

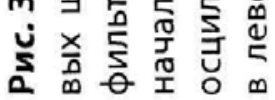




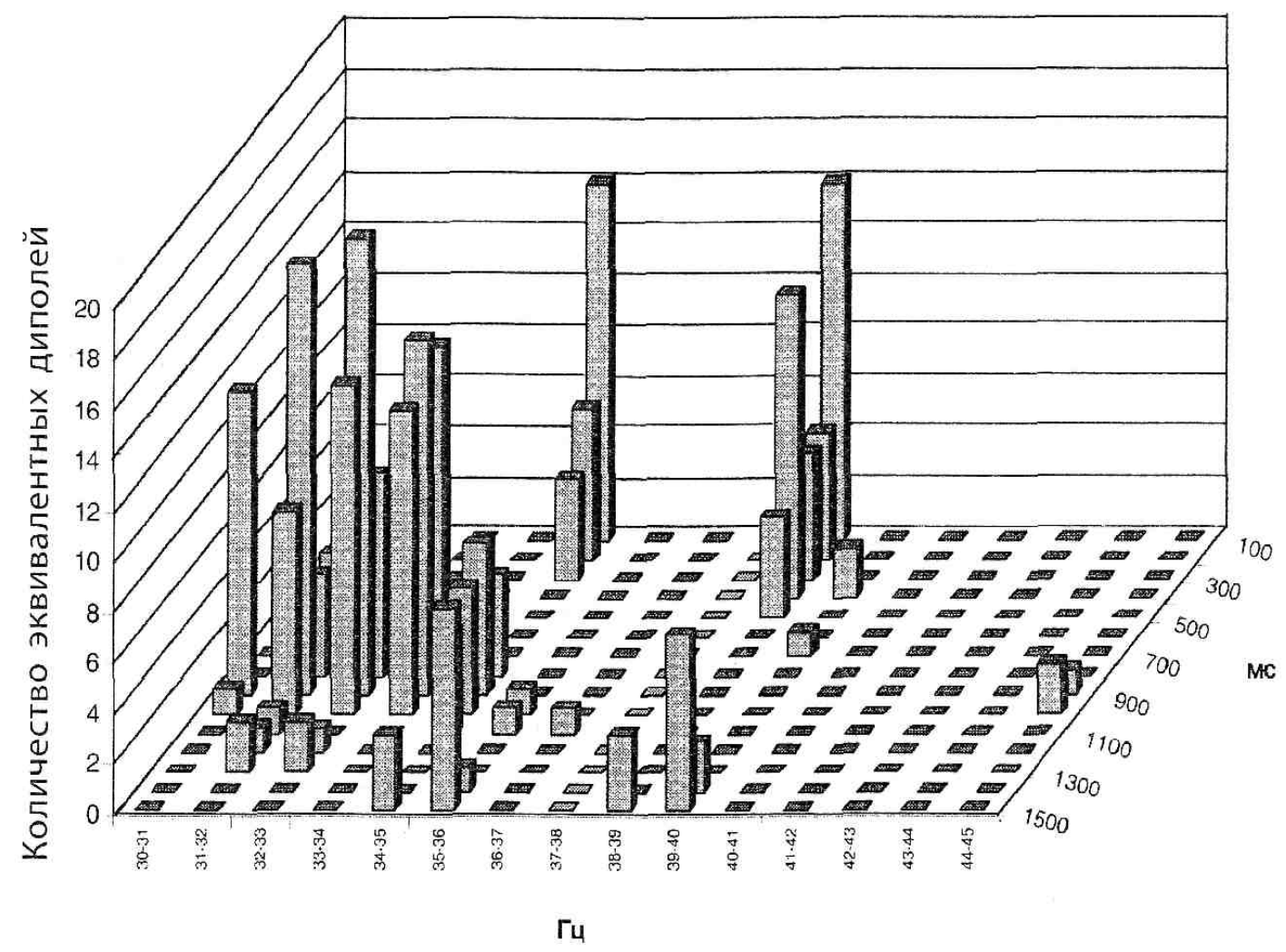

Рис. 4. Гистограмма частотно-временного распределения активности узкополосных гамма-осцилляторов в составе усредненной ЭЭГ относительно звукового щелчка дительностью в 1,5 с у исп. М.С. в пределах частотного диапазона от 30 до 45 Гц. Количество эквивалентных диполей - мера активности гамма-осцилляторов. Активность осциллятора определяется для каждого временного окна в 100 мс. Горизонтальная шкала - частота узкополосных гамма-осцилляторов

Видно, что на начальном участке звукового УВП активированы только два осциллятора, работающих на частотах 38-39 и 34-35 Гц. На этих же частотах представлена и реакция антиципации (во временном окне 1400-1500 мс). На интервале 800-1000 мс после стимула активированы гамма осцилляторы более низкой частоты (от 30-31 до 33-34 Гц). В каждом временном окне работает только часть гамма осцилляторов, настроенных на определенные частоты. $\mathrm{C}$ изменением временного окна состав активных гамма осцилляторов меняется. Таким образом, появление активности у узкополосного гамма осциллятора в составе УВП зависит от его частотной настройки и временного окна после стимула. Это позволяет рассматривать активность гамма-ритма как частотно-избирательный процесс. 
Применение метода узкополосной фильтрации к более высокочастотному диапазону гамма-ритма (55-75 Гц) позволило обнаружить частотную избирательность и у гамма осцилляторов, настроенных на более высокие частоты. На рис.5 представлены индивидуальные гистограммы

частотно-временного распределения активности узкополосных гамма осцилляторов в составе усредненной ЭЭГ, полученной на многократное предъявление через наушники пар чисел для их перемножения. Гистограммы построены для двух частотных диапазонов: 30-45 Гц (А) и 55-75 Гц (Б). Видно, что ранний сенсорный ответ гаммаритма представлен активностью двух низкочастотных осцилляторов, настроенных на 34-35, 35-36 Гц и двух высокочастотных, работающих на частотах 58-59 и 64-65 Гц. Группы активированных гамма осцилляторов на других частотах привязаны к более поздним временным окнам (600-1000 мс).

Избирательный характер активности узкополосных гамма осцилляторов выявлен и в составе усредненной ЭЭГ, полученной на зрительный целевой стимул - появление на экране монитора яркого светового квадрата, на который нужно было реагировать нажимом на клавишу клавиатуры компьютера (рис. 6). В обеих частотных зонах активация гамма осцилляторов с острой настройкой носит избирательный характер и привязана к определенным временным окнам усредненной ЭЭГ.

Наложение рассчитанных координат эквивалентных дипольных источников узкополосных гамма осцилляторов на структурные магнитно-резонансные томограммы мозга испытуемых позволяет с большей степенью точности выявлять структуры мозга, вовлекаемые в процесс восприятия. Совмещение дипольного анализа с методом анатомической могнитно-резонансной томографии показало, что дипольные источники каждого частотно-специфического гамма осциллятора, активированного в составе сенсорного ответа, появляются в одном или нескольких локальных участках мозга. Их расположение на томографических срезах зависит от частоты гамма осциллятора. Активность разночастотных гамма осцилляторов привязана к разным локусам. 
a)

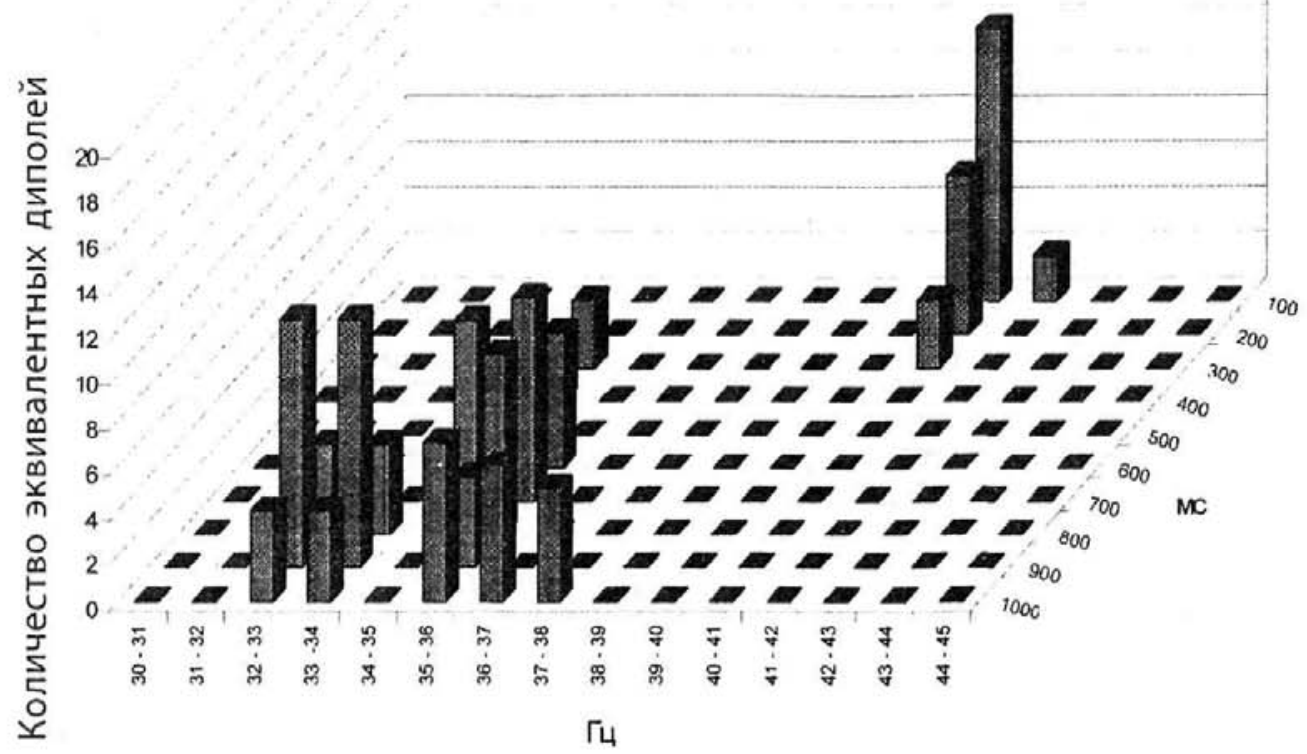

๑)

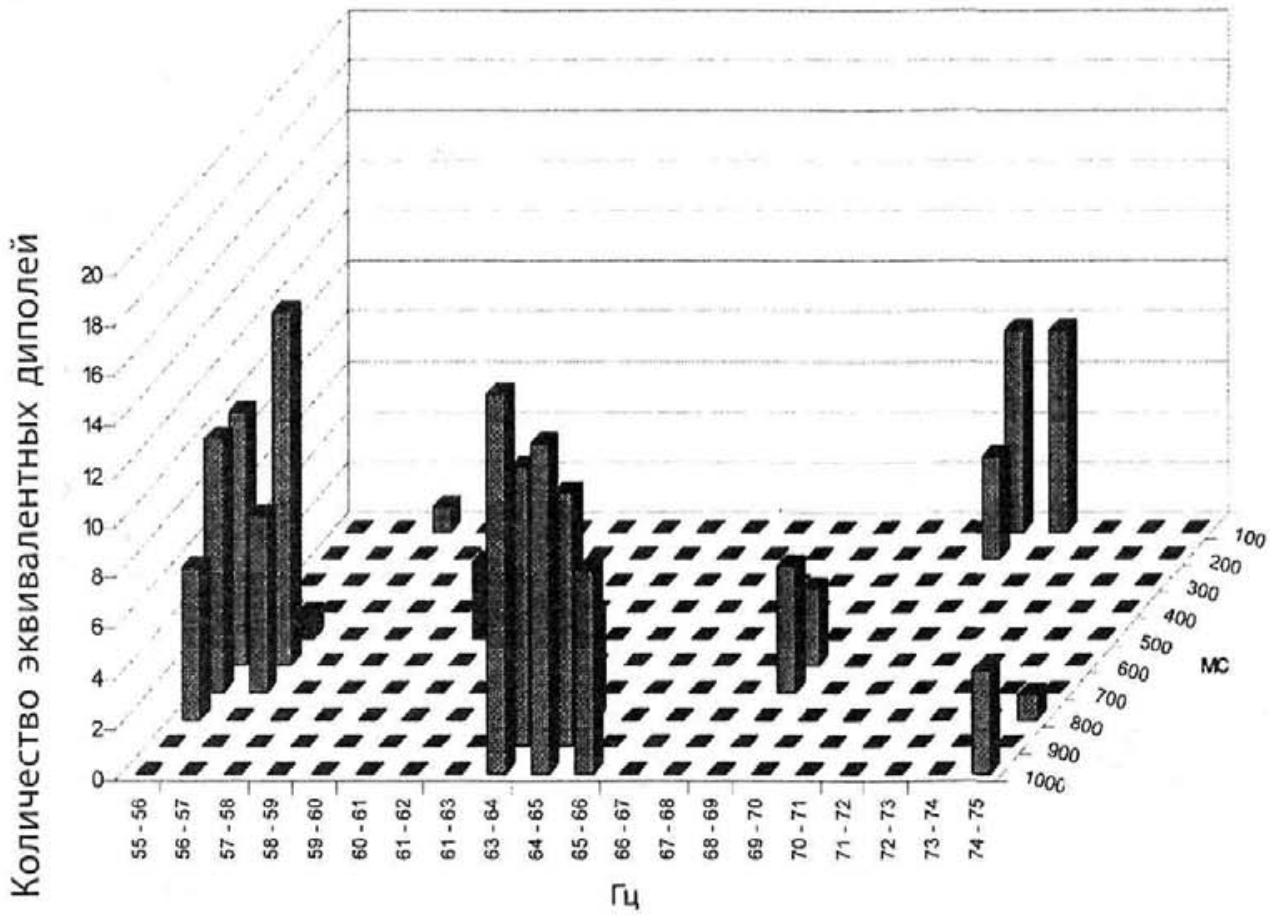

Рис. 5. Гистограммы частотно-временного распределения активности узкополосных гамма-осцилляторов в составе усредненной ЭЭГ длительностью в 1000 мс, полученных на многократное предъявление через наушники пар двухзначных чисел для перемножения у исп. Г.И. в двух частотных диапазонах: 30-45 Гц (а) и 55-75 Гц (б) (остальные обозначения см. рис. 2) 
a)

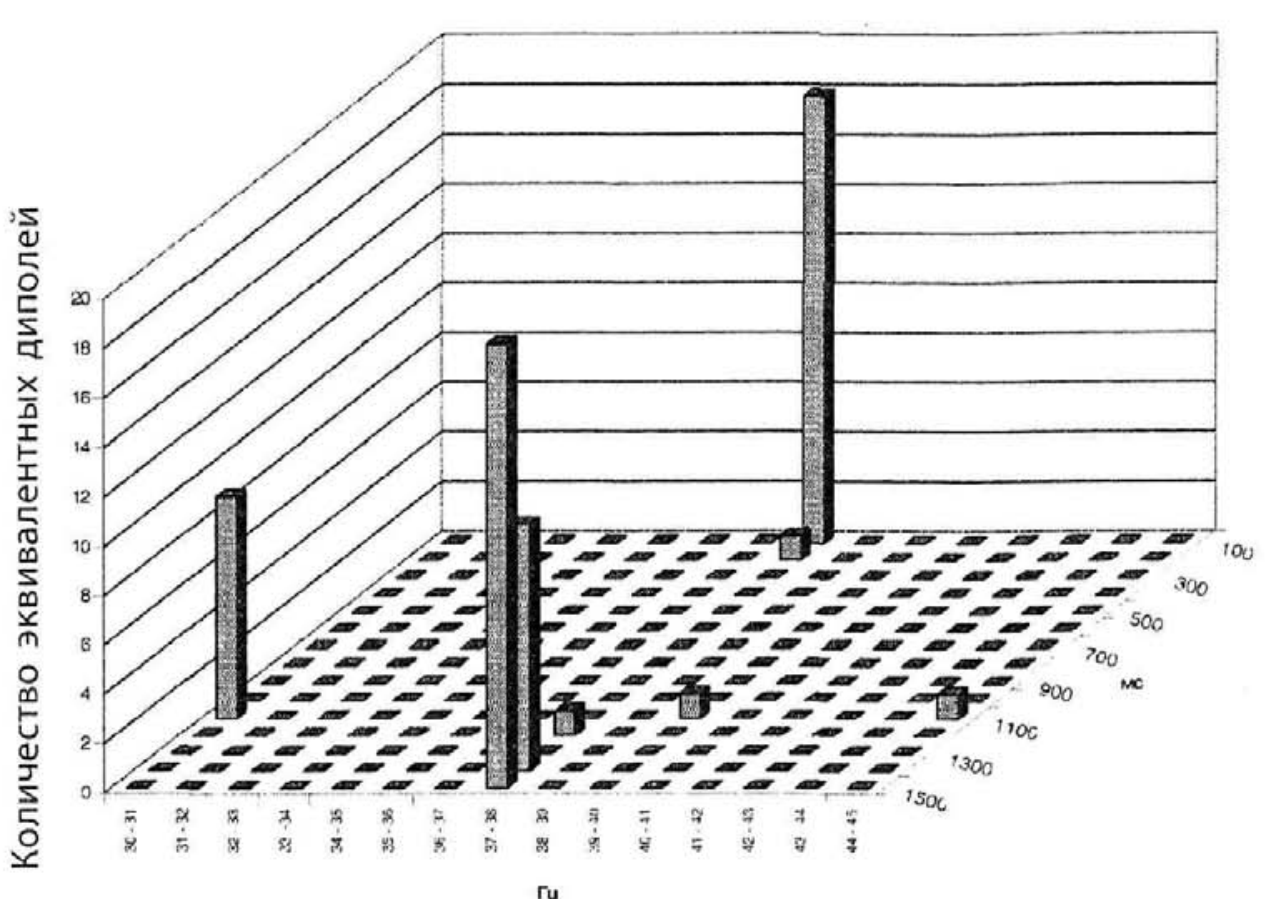

๑)

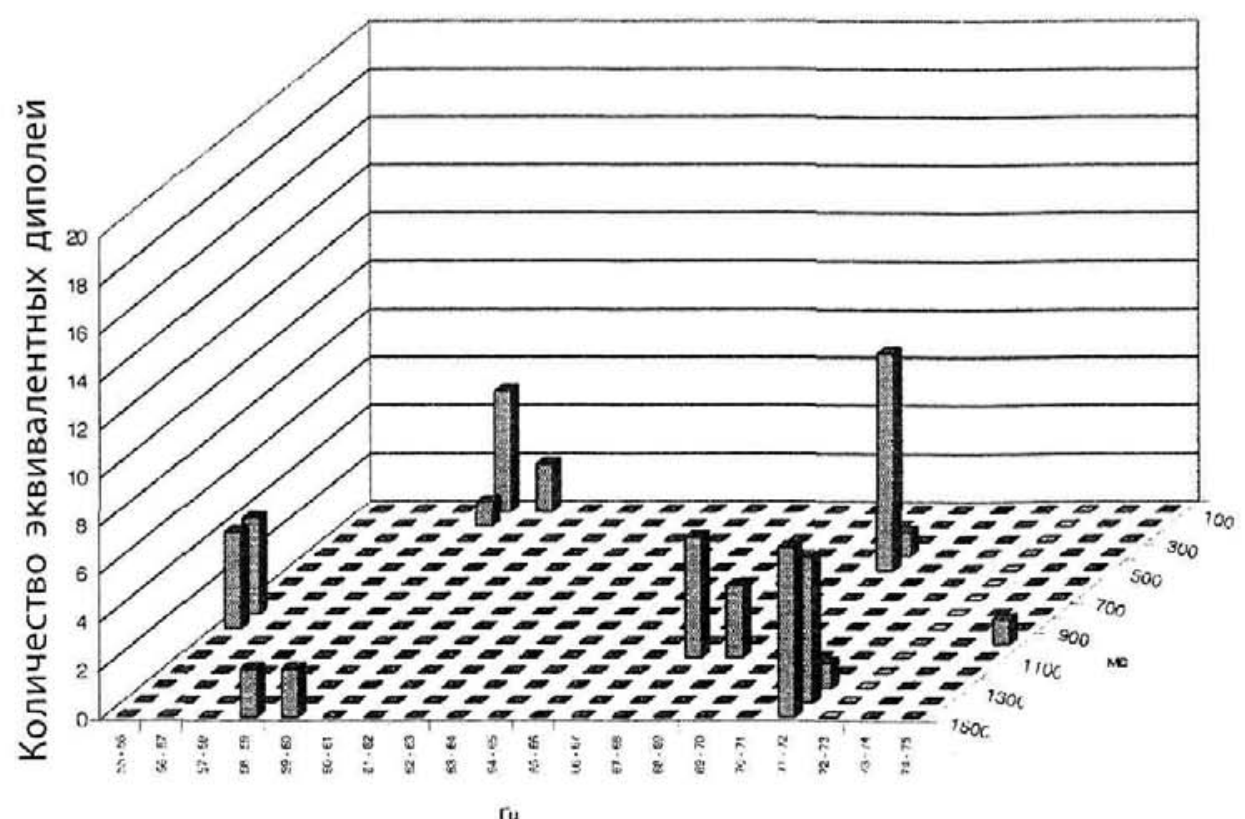

Рис. 6. Гистограммы частотно-временного распределения активности узкополосных гамма-осцилляторов в составе усредненной ЭЭГ длительностью в 1500 мс, полученных на предъявление зрительного целевого стимула у исп. М.Л. в двух частотных диапазонах 30-45 Гц (a) и 55-75 Гц (б) (остальные обозначение см. рис. 2). 
При выполнении сенсомоторной реакции на выключение звука диполи активных гамма осцилляторов найдены в двух локальных участках мозга. У активированных гамма осцилляторов, работающих на разных частотах, позиции двух зон на томограммах мозга не совпадают. На рис. 7 a, б представлена

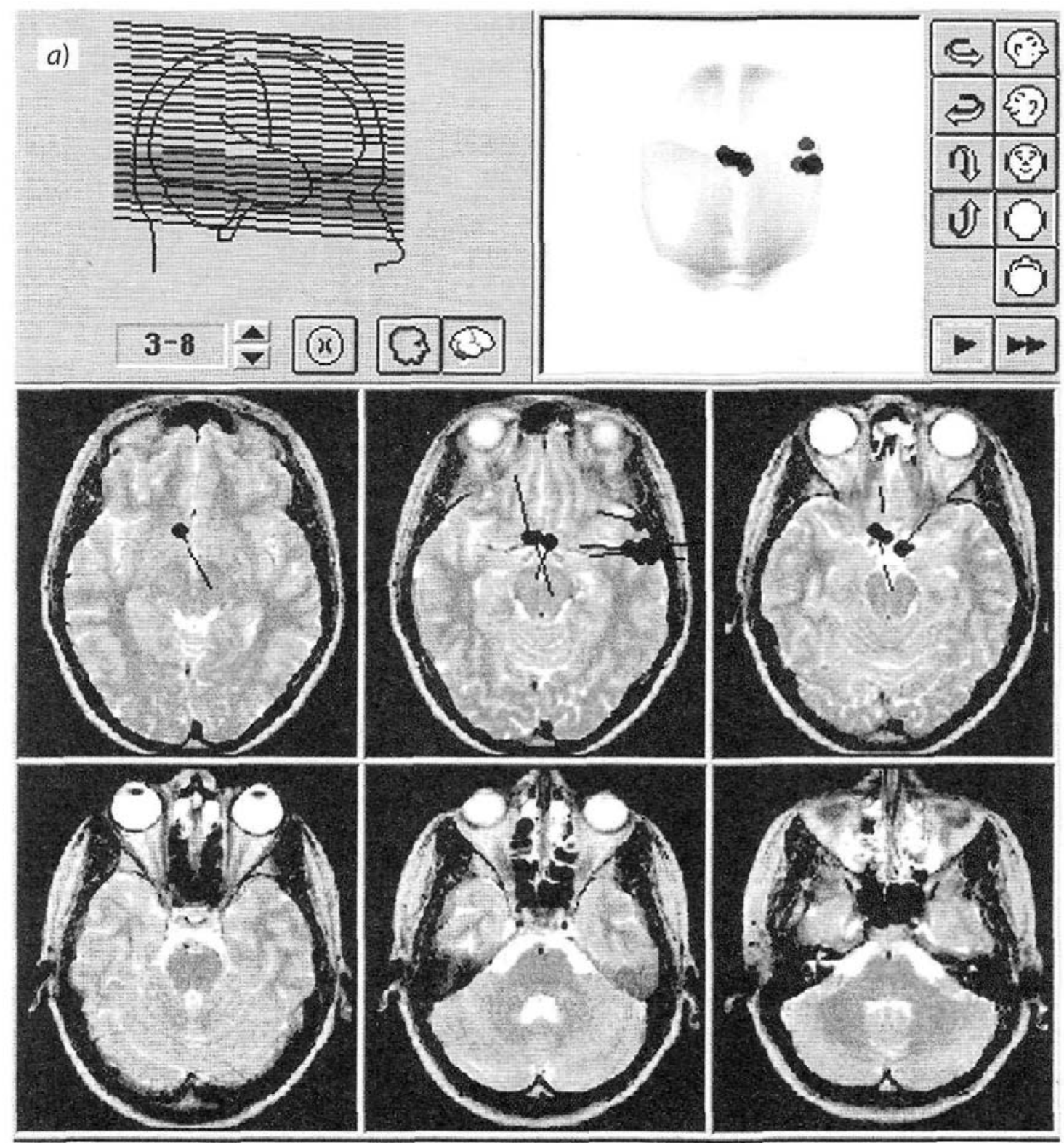

Рис. 7a. Локализация эквивалентных диполей двух узкополосных гамма-осцилляторов на структурных магнитно-резонансных томограммах исп. М.С., работающих на частотах 34-35 Гц (a) и 33-34Гц (б). Каждый из двух гаммаосцилляторов с острой настройкой на протяжении 100 мс активирован в двух пространственно разделенных участках мозга 

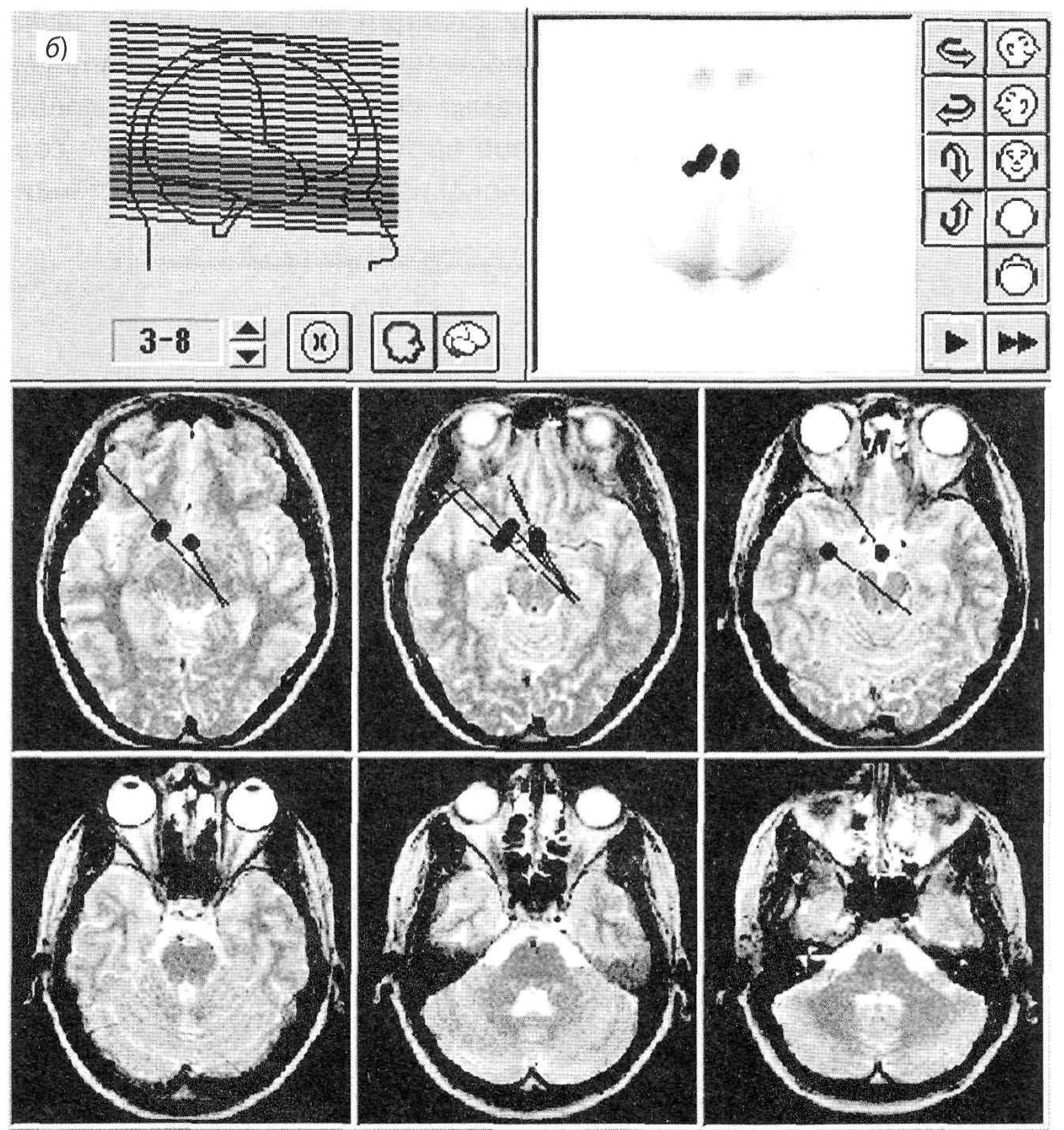

Рис. 76

локализация дипольных источников двух гамма осцилляторов с частотой 34-35 Гц (А) и 33-34 Гц (Б) на томографических срезах мозга исп. М.С. Видно, что позиции эквивалентных диполей двух гамма осцилляторов сдвинуты относительно друг друга. Источники гамма осциллятора с частотой 33-34 Гц в большей степени представлены в левом полушарии, тогда как у осциллятора с частотой 34-35 Гц они появляются в правой височной коре и нижней лобной, ближе к медиальной поверхности. 
Для изучения взаимодействия разночастотных гамма осцилляторов была исследована их временная динамика на начальном участке УВП. У всех обследуемых на протяжении сенсорного ответа (на интервале 0-100 мc) активация гамма осцилляторов характеризуется периодичностью, общей для разночастотных осцилляторов. За счет временной синхронизации вспышек гамма осцилляторов, работающих на разных частотах, создается общий ритм их совместной деятельности в виде чередования периодов активации и инактивации. На рисунке 8 представлено периодическое появление дипольных источников в структурах мозга для каждого из активно работающих узкополосных гамма осцилляторов на начальном участке звукового УВП (0-100 мс после стимула) у одного из испытуемых. Наличие эквивалентного диполя - показатель активности гамма осциллятора. Видно, что два гамма осциллятора, активированных у человека в индиферентной серии, возбуждаются периодически. Активность узкополосных гамма осцилляторов во времени синхронизирована. На интервале в 0-100 мс возникает 8 вспышек совместной активности гамма осцилляторов, создавая ритм на частоте около 120 Гц. В моторной серии периодическая синхронизация разночастотных осцилляций формирует 6 периодов активности и паузы между ними.

Впервые были получены результаты, подтверждающие дискретный характер активности гамма осцилляторов, настроенных на очень узкие полосы частот шириной, не превышающей 1 Гц. Дискретность их активности выявлена как по частотной шкале, так и во времени. Полученные данные о частотной специфичности гамма осцилляторов с острой частотной настройкой, в целом согласуются с результатами других исследователей, сообщавших о негомогенности гамма ритма на основе фактов о независимости изменений отдельных участков спектра мощности гамма-ритма [5, 21, 42 и др.]. Вместе с тем результаты настоящего исследования подчеркивают важность изучения функций не широкополосных, а узкополосных гамма осцилляторов в реализации сенсорных и когнитивных процессов. Правомерность такого утверждения основывается на том, что дискретный характер гамма осцилляторов более выражен у узкополосных, чем у широкополосных осцилляторов и, что число активированных гамма осцилляторов с острой настройкой (шириной в 1 Гц) в десятки раз превосходит число осцилляторов при расширении полосы частотной фильтрации до 15 Гц. 

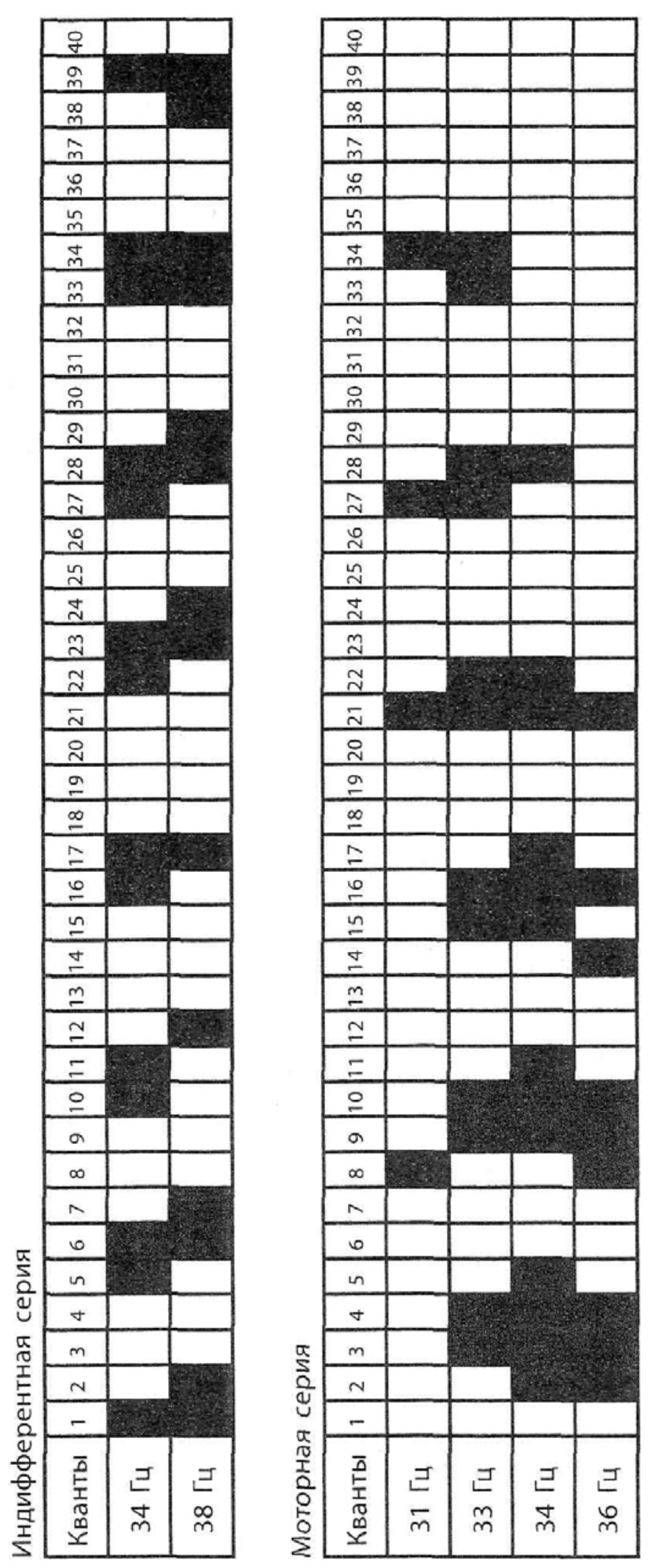

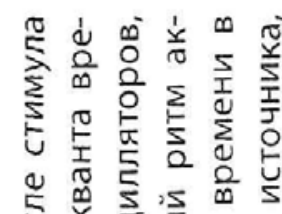

ᄃ

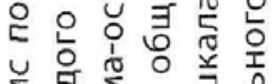

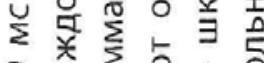

오 잉 인

पू $\frac{5}{5} \frac{5}{5}$

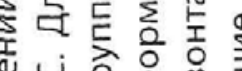

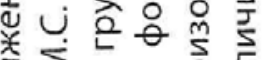

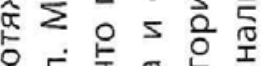

든

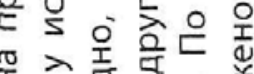

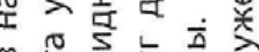

동 ڤ

范

눙응

的的足

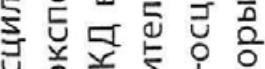

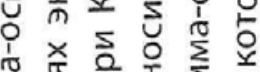

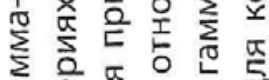

닌 원존

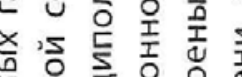

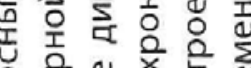

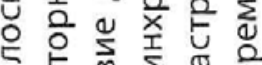

응

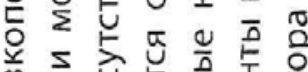

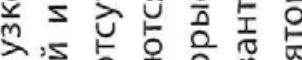

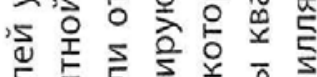

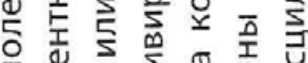

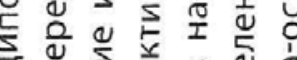

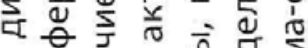

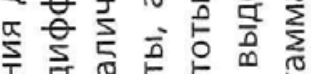

I I I I

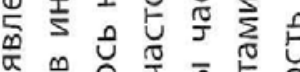

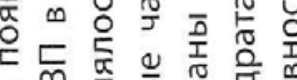

들

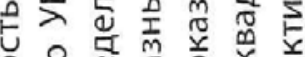

은 융

군은

近

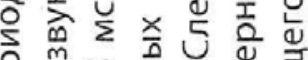

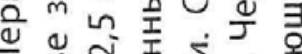

늄

$\infty$ 空舟

ن 
Представленные результаты об активности узкополосных гамма осцилляторов при работе со звуковыми щелчками, при восприятии пар двухзначных чисел для перемножения, а также целевых зрительных стимулов выявляют их общую черту. Узкополосные гамма осцилляторы работают как частотно-специфические и независимые системы. Они обнаруживают модуляцию своей активности во времени, которая в нашем исследовании в результате применения дипольного анализа проявляется как дискретность их активности на протяжении всего УВП. Активность осцилляторов возникает в одних временных окнах и отсутствует в других. Кроме того выявлена привязка активности частотно-специфических гамма осцилляторов, работающих на разных частотах, к различным локусам в структурах мозга.

Появление дипольных источников гамма осциллятора, избирательно настроенного на определенную частоту, в двух локусах на томограммах, можно рассматривать как выражение взаимодействия двух участков мозга, вовлекаемых в общую функцию через механизм синхронизированных гамма осцилляций на общей частоте. Как показывают наши результаты, подобный процесс взаимодействия присутствует уже на самых ранних стадиях восприятия звукового стимула - на интервале 0-100 мс после его предъявления. Можно высказать предположение, что узкополосные гамма осцилляторы выполняют коммуникативную функцию, обеспечивая участие памяти и вовлечение функций префронтальной коры в процесс сенсорного кодирования [2, 3]. Они объединяют сенсорные процессы с процессами памяти уже в составе сенсорного ответа, обеспечивая слияние двух потоков информации: "bottom-up" и "top-down".

Выявлено две формы проявления коммуникативной функции гамма-ритма: связывание структур мозга в единую функциональную систему осуществляется как за счет общей частоты гаммаосцилляторов , активируемых в связываемых структурах мозга, так и за счет механизма временной синхронизации активности группы разночастотных узкополосных гамма осцилляторов, создающих общий ритм чередования периодов активации и инактивации.

Что представляет собой механизм, определяющий частотную избирательность настройки гамма осцилляторов? Важным шагом на пути изучения механизмов генерации гамма-ритма стала внутриклеточная регистрация идентифицированных вставочных и пирамидных нейронов гиппокампа. Выявлены кластеры вставочных нейронов, генерирующих синхронизированные спайки высокой 
частоты, модулирующих состояние пирамидного нейрона, с которым они связаны. Синхронизированные разряды вставочных нейронов совпадали с колебаниями фокального потенциала, который рассматривается как суммарная характеристика состояния локальной группы функционально взаимодействующих нейронов [43]). Так как частота колебаний фокального потенциала соответствует частотному диапазону гамма-ртима $[34,35]$ можно предположить две модели, объясняющих генерацию узкополосного гамма-ритма. Согласно одной версии, сигнал, поступающий к вставочным нейронам запускает процесс их взаимодействия, который создает резонансный эффект на группе нейронов, включенных в общую функцию. Частота кластера взаимодействующих вставочных нейронов определяется частотой потенциалов действия доминирующего вставочного нейрона Согласно другой гипотезе, вставочные нейроны обладают пейсмекерными свойствами. Сигнал, приходящий к ним, переводит их в режим пейсмекерной активности, одновременно вызывая перезапуск их спайковых разрядов, что и обеспечивает эффект синхронизации активности группы вставочных нейронов, который порождает гаммаритм определенной частоты в локальном клеточном ансамбле [7].

Таким образом, по-видимому, существует частотноспецифический механизм кодирования информации, который базируется на частотной избирательности пейсмекерной активности вставочных нейронов, обуславливающих связывание (binding) структур мозга для реализации психических функций.

Разные участки мозга характеризуются разной частотой пейсмекерных потенциалов вставочных нейронов, которая может быть выделена из вызванного потенциала методом частотной фильтрации. Локализация пейсмекерных вставочных нейронов в разных отделах мозга достигается расчетом положения частотноспецифического эквивалентного диполя.

Таким образом, экспериментальное исследование локализации эквивалентных диполей узкополосных гамма осцилляторов мозга человека, активированных в составе УВП, привело к заключению, что частотный состав осцилляторов образует дискретный ряд, а не сплошной спектр. Эквивалентный диполь на определенной частоте возникает последовательно во временных окнах, отстоящих друг от друга на фиксированный интервал. В одном и том же участке мозга и в одном и том же временном окне могут возникать разные по частоте диполи. Можно предположить, что каждому частотно-селективному диполю соответствует группа пейсмекерных вставочных нейронов, представляющих стимул своей активацией на определенном отрезке 
времени. Одномоментное возникновение нескольких частотно селективных диполей в локальном участке мозга свидетельствует о функционировании там нескольких групп вставочных нейронов. Смещение положения диполей означает подключение новой мозговой структуры.

Соединение методов УВП, дипольного анализа и анатомической магнитно-резонансной томографии для изучения узкополосных гамма осцилляторов позволило выявить две формы проявления коммуникативной функции вызванного гамма-ритма. Связывание структур мозга в единую функциональную систему осуществляется как за счет общей частоты, на которую настроены гамма осцилляторы, активируемые в связываемых структурах мозга, так и за счет механизма временной синхронизации активности группы разночастотных узкополосных гамма осцилляторов, создающих общий ритм чередования периодов активации и инактивации.

\section{Литература}

1. Данилова Н.Н. Гамма-осцилляции в когнитивной деятельности человека//XXX Всероссийское совещание по проблемам высшей нервной деятельности, посвященное 150 -летию со дня рождения И.П.Павлова. Санкт-Петербург. 2000. 63-66

2. Данилова Н.Н., Быкова Н.Б., Анисимов Н.В., Пирогов Ю.А., Соколов Е.Н. Гамма-ритм электрической активности мозга человека в сенсорном кодировании//Биомедицинская радиоэлектроника.2002, №3, 34 34-42

3. Данилова Н.Н., Быкова Н.Б. Роль частотно-специфических кодов в процессах внимания// Материалы 2-ой Международной конференции, посвященной 100-летию со дня рождения А.Р. Лурия «А.Р. Лурия и психология XXI века»М. «Федоровец», 2003, (в печати)

4. Данилова Н.Н., Быкова Н.Б. Осцилляторная активность мозга и информационные процессы //Психология: современные направления междисциплинарных исследований. Доклады конференции, М. Из-во ИПРАН. 2003 (в печати)

5. Думенко В.Н., М.К.Козлов Исследование селективного внимания у собак по данным когерентно-фазовых характеристик корковых потенциалов в широкой полосе частот 1-220 Гц//Журн. высш.нервн.деят., 2002, №4, 428-440

6. Думенко В.Н., Функциональное значение высокочастотных компонентов электрической активности головного мозга в 
процессах формирования внутренних образов//Журн. высш.нервн.деят., 2002, №5, 539-550

7. Соколов Е.Н. Восприятие и условный рефлекс: новый взгляд. 2003, МГУ (в печати)

8. Basar. E. Brain function and oscillations. II: Integrative brain function. Neurophysiology and cognitive processes. 1999. Springer

9. Basar E., Basar-Eroglu C., Karakas S., Schurman M. Brain oscillation in perception and memory//International Journal of Psychophysiology 35: 95, 2000

10. Bresslerr, S.L. Large-scale cortical networks and cognition //Brain Research Reviews, 1995, 20, 288-304

11. Brosch M., Bauer R., and Eckhorn R. Stimulus-dependent modulations of correlated high- frequency oscillations in cat visual cortex //Cereb Cortex, 1997, 7, 70-76 [цитировано по MEDLINE]

12. Eckhorn,R., Bauer, R., Jorden, W., Brosch, M., Kruse, W., Munk, M.H.J. \& Reitboeck, H.J. Coherent oscillations: a mechanizm of feature linking in the visual cortex? Multiple electrode and correlation analysises in the cat //Biological Cybernetics, 1988, 60, 121-130

13. Eckhorn,R., Reitboeck, H.J., Arndt, M. And Dickt, P.Feature linking via synchronization among distriuted assemblies: Simulations of results from cat visual cortex//Neural Computetion 2, 293, 1990.

14. Ekhorn,R., Frien A., Bauer R., Woelbern T. And Kehr H. Highfrequency $(60-90 \mathrm{~Hz})$ oscillations in primary visual cortex of awake monkey //NeuroReport, 1993, 4, pp 243-246 [цитировано по MEDLINE]

15. Fell J., Hinriche H., Roschke J. Time-course of human $40 \mathrm{~Hz}$ EEG activity accompanying P3 responses in an auditory oddball paradigm. // Neurosci. Lett. 1997, Vj1 235, Iss 3, pp 121-124

16. Frien A., Eckhorn R., Bauer R., Woelbern T. And Kehr Stimulusspecific fast oscillations at zero phase between visual areas V1 and V2 of awake monkey //NeuroReport, 1994, 5, pp 22722277[цитировано по MEDLINE]

17. Fries, P., Roelfsema P.R., Engel A. K., Koning P. \& Singer W. Sinchronization of oscillatory responses in visual cortex correlates with perception in interocular rivalry//Proceedings of the National Academy of Science USA, 1997, 94, 12699-12704

18. Galambos, R. A comparison of certain gamma band (40-HZ) brain rhythms in cat and man//In E. Basar \& T.H. Bullak (Eds) Induced Rhythms in the Brain, 1992, 201-206. Boston: Brikhauser 
19. Herculano-Houzel, S., Munk M.H.J., Neuenschwander, S. \& Singer W. Precisely synchronizeed oscillatory firing patterns require electroencephalographic activation//J. Of Neuroscience, 1999, 19, 3992-4010

20. Herrman, C.S., Mecklinger, A. \& Pfeifer, E. Gamma response and ERPs in visual classification task// Clin. Neurophysiol. 1999, 110, 636-642

21. Hughes J.R., Hendrix D., Weizel N. And Johnson J. Correlations between electrophysiological activity from the human olfactory bulb and subjective response to odoriferous stimuli//In Pfaffman C. (Eds) Olfaction and taste. III, 1969, pp. 172-191. Oxford: Pergamon

22. Jones M.S., Barth D.S. Sensory-evoked high-frequency (gammaband) oscillating-potentials in somatosensory cortex of the unanesthetized rat //Brain Research, 1997, Vol. 768, Iss 1-2, pp 167176

23. Kojo I., Liinasuo, M and Rovamo, J. (1993) Spatial and temporal properties of illusory figures. Vision Res., 33: 897-901.

24. Laurent G., Wehr M., Davidowitz A. Temporal representation of odors in an olfactory network//J. Neurosci. 1996, 16: 3837-3847

25. Lutzenberger W., Pulvermuller F., Birbaumer N. Words and pseudowords elicit distinct patterns of $30-\mathrm{Hz}$ activity in humans //Neurosci. Lett. 176, 115. 1994

26. Koseki K., Yamanouchi N., Sato T., Nakajima Y. Attention Changes the Peak Latency of the Visual Gamma- Band Oscillation of the EEG //NEUROREPORT 1999, Vol 10, Iss 6, pp 1167-1170

27. Mima T., Simpkins N., Oluwatimilehin T., Hallett M. //Force Level Modulates Human Cortical Oscillatory Activities //NEUROSCIENCE LETTERS 1999, Vol 275, Iss 2, pp 77-80

28. Neuenschwander S. and Singer W. Long-range synchronization of oscillatory light responses in the cat retina and lateral geniculate nucleus//Nature 1996, 379: 728-732

29. Popivanov D., Mineva A., Krekule I. EEG Patterns in ThetaFrequency-Range and Gamma-Frequency-Range and Their Probable Relation to Human Voluntary Movement Organization //NEUROSCIENCE LETTERS 1999, Vol 267, Iss 1, pp 5-8

30. Pulvermuller, F., Preissl, H., Lutzenberger, W. and Birbaumer, N. Spectral responses in thr gamma-band: physiological signs of higher cognitive processes? //NeuroReport. 1995. 6. 2057.

31. Sannita W.G. Stimulus-specific oscillatory responsess of the brain: a time/frequency-related coding process//Clinical Neurophysiology, V.111, Issue 4, Aprill 2000, P. 565-583 
32. Shibata T., Shimoyama I., Ito T., Abla D., Iwasa H., Koseki K., Yamanouchi N., Sato T., Nakajima Y. Event-Related Dynamics of the Gamma-Band Oscillation in the Human Brain - InformationProcessing During a Go/Nogo Hand Movement Task//NEUROSCIENCE RESEARCH 1999, Vol 33, Iss 3, pp $215-$ 222

33. Singer W. Response synchronization of cortical neurons: an epiphenomenon or a solution to the binding problem? //Ibro News. 1991. V.19.№1.P. 6

34. Singer W. and Gray C.M. Visual feature integration and the temporal correlation hypothesis //Annu. Rev. Neurosci. 1995: 18. 555-586.

35. Singer, W. Neurobiology: striving for coherance//Nature, 1999, 397, 391-392

36. Spydel J.D., Ford M.R., and Sheer D.E. Task dependent cerebral lateralization of the $40 \mathrm{~Hz}$ EEG rhythm //Psychophysiology.1979. 16. P. 347-350.

37. Stopfer M., Bhagavan S., Smith B.H., Laurent G. Impaired odour discrimination on desinchronization of odour-encoding neural assemblies//Nature 1997, 390:70-74

38. Tallon-Baudry,C., Bertrand,O.,Bouchet,P. And Pernier,J. Gammarange activity evoked by coherent visual stimuli in humans //Eur $\mathrm{J}$ Neurosci. 1995, 7, 1285-1291

39. Tallonbaudry C., Kreiter A., Bertrand O. Sustained and Transient Oscillatory Responses in the Gamma-Band and Beta-Band in a Visual Short-Term-Memory Task in Humans //Visual Neuroscience 1999, Vol 16, Iss 3, pp 449-459

40. Tiitinen, H., Sibkkonen, J., Reinkainen, K., Alho, K., Lavikainen, J., Naatanen, R. Selective attention enhances the auditory $40-\mathrm{Hz}$ transient response in humans //Nature, 1993, 364, 59-60.

41. Von der Malsburg, C. \& Schneider, W. Binding in models of perception and brain function//Current Opinion in Neurobiology, $1995,5,520526$

42. Wehr M. And Laurent G. Oduor encoding by temporal sequences of firing in oscillating neural assemblies//Nature 1996, 384: 162-166

43. Ylinen A., Bragin A., Nadasdy Z., Jando G., Szabo I., Sik A. And Bazsaki Sharp wave-associated high-frequency oscillation $(200 \mathrm{~Hz})$ in the intact hippocampus: network and intracellural mechanisms $/ / \mathbf{J} /$ Neirosci. 1995, V. 15, 30-46

44. Yordanova, J., Kolev, V. \& Demiralp, T. The phase-locking of auditory gamma band responses in humans is sensitive to task processing//NeuroReport, 1997, 8, 3999-4004. 